Article

\title{
Antioxidants in Different Potato Genotypes: Effect of Drought and Wounding Stress
}

\section{Christina B. Wegener * and Gisela Jansen}

Julius Kühn-Institute, Federal Research Centre for Cultivated Plants, Institute for Resistance Research and Stress Tolerance, Rudolf-Schick-Platz 3, D-18190 Sanitz, Germany;

E-Mail: gisela.jansen@jki.bund.de

* Author to whom correspondence should be addressed; E-Mail: christina.wegener@jki.bund.de; Tel.: +49 38209 45-211; Fax: +49 38209 45-120.

Received: 29 November 2012; in revised form: 16 February 2013 / Accepted: 17 February 2013 / Published: 28 February 2013

\begin{abstract}
Potatoes are regarded as a significant antioxidant source in human nutrition. However, different types of environmental stress may affect the level of antioxidants in their tuber tissue. In this study, two purple breeding clones and the yellow fleshed cultivar (cv.) Agave were grown in the glasshouse under control with drought stress conditions for two consecutive years. After harvest, the tubers were analysed for concentrations of antioxidants measured as ascorbic acid equivalent (ACE) and trolox equivalent (TXE) in fresh tissue and after wounding. In addition, the peroxidase enzyme (POD) activities and total amounts of anthocyanins (Ac) were assayed. Drought stress caused a significant decrease in tuber yield but had no significant effect on Ac, POD, ACE and TXE. Wounding stress significantly induced the POD activity in control and drought stressed tubers of all genotypes. Also the ACE and TXE were notably increased by wounding in cv. Agave. This was less pronounced in the purple clones which in general displayed a higher level of antioxidants. The results revealed significant differences between genotypes and that the effect of drought stress on the level of antioxidants is smaller than that of wounding stress.
\end{abstract}

Keywords: tuber yield; quality; anthocyanins; peroxidase; antioxidants; abiotic stress 


\section{Introduction}

Antioxidants are gaining increasing attention in human nutrition, mainly due to growing incidence of chronic and degenerative diseases such as diabetes, arteriosclerosis, inflammation, stroke, cancer, rheumatoid arthritis, brain dysfunction, etc. [1]. Epidemiological studies have revealed that fruits and vegetables have a protective effect against various types of cancer [2], e.g., pancreas, stomach, colorectal, bladder, breast and ovary cancer [3]. It has been argued that cancer can be prevented by a combined action of many compounds [4], especially those with antioxidant activity which may contribute to the overall effect [5]. Significantly increased fruit and vegetable intake resulted in significant reductions in the marker of oxidative cellular damage to DNA and lipids [4]. The major antioxidants in plant tissue are superoxide dismutase, catalase, ascobate peroxidase and glutathione reductase, and there are low molecular weight antioxidants like ascorbate (Vitamin C), tocopherols (Vitamin E), carotenoids, plant phenols such as hydroxycinnamates and flavonoids including anthocyanins [6].

Also potatoes have received substantial interest as a valuable source of antioxidants $[7,8]$ because they contain a variety of secondary metabolites including plant phenols and are consumed in relatively high amounts [9]. Therefore, it is important for breeding to identify genotypes rich in antioxidants [7]. Above all, purple fleshed potatoes contain high amounts of anthocyanins and plant phenols, mainly chlorogenic acid [10-12], i.e., all components with a strong antioxidant activity and potential beneficial effects on human health [13]. Antioxidant activity is regarded to be the major function of plant phenols [6]. A clear relationship between antioxidants and phenols was also reported for several cultivated and wild Solanum species [12,14]. In plants, the antioxidant activity can mitigate effects of abiotic and biotic stress by scavenging reactive oxygen species (ROS), protecting antioxidant enzymes and interacting with other molecules within the signal transduction pathway $[6,15]$. As a substantial part of the plant antioxidant system, plant phenols can diminish undesired effects of oxidative stress on metabolism and cells, and in humans they may create several therapeutic effects as antioxidant, anticarcinogen and cardioprotective agents when consumed with the diet [13,15]. Thus, consumption of purple flesh potatoes led to an increase in plasma and urine antioxidant capacity and significantly decreased blood pressure [16]. With it, the concentration of antioxidants in tuber tissue can be seen as an important quality factor of potatoes. However, in nature plants are exposed to severe environmental stresses, and adaptation is essential for their survival. Plant phenols and antioxidants are inducible by environmental stress [17], and the appropriate plant stress responses may be associated with changes in the level of all these components.

It was interesting therefore, to study the effect of drought and wounding stress as two of the major environmental stresses for plants in agriculture on antioxidants accumulated in tuber tissue. In this work, one yellow fleshed commercial cultivar (cv. Agave) and two purple breeding clones (St 89403 and St 3792) were grown in the glasshouse under control and drought stress conditions in 2010 and 2011. After harvest, the tuber yield was determined and the tubers of the two variants were analysed for water (ACE, ascorbic acid equivalent) and lipid soluble antioxidants (TXE, Trolox equivalent) present in their fresh tissue and generated after wounding, using a photo-chemiluminescent (PCL) method. In addition, peroxidase enzyme (POD) activities were assayed, and the total amounts of anthocyanins were analysed in lyophilized tissue samples derived from tubers grown under control and 
drought stress conditions. Finally, the relation between antioxidants and the last two components mentioned was evaluated.

\section{Results and Discussion}

\subsection{The Effect of Drought Stress on Tuber Yield}

The potato plants were grown in a glasshouse. The mean temperatures during the growing periods are presented in Table 1. In both test years, the tuber yield of all three potato genotypes was decreased when plants were exposed to drought stress during growth (Table 2). The average reduction of tuber yield was statistically significant when all genotypes and years were regarded, within the genotypes with years at a level of $P \leq 0.05$.

Table 1. Mean temperature during the growing season in 2010 and 2011.

\begin{tabular}{ccc}
\hline & \multicolumn{2}{c}{ Temperature $\left({ }^{\circ} \mathbf{C}\right)$} \\
Month & $\mathbf{2 0 1 0}$ & $\mathbf{2 0 1 1}$ \\
\hline May & 9.7 & 12.8 \\
June & 15.1 & 16.1 \\
July & 20.6 & 17.0 \\
August & 17.1 & 17.1 \\
September & 12.8 & 14.7 \\
\hline
\end{tabular}

Table 2. Tuber yield of control and drought stressed plants and reduction of yield caused by drought stress (Mean $\pm \mathrm{SD} ; n=4$ ).

\begin{tabular}{ccccc}
\hline \multirow{2}{*}{ Years } & \multirow{2}{*}{ Genotypes } & \multicolumn{2}{c}{ Yield (g per plant) } & Yield reduction \\
\cline { 3 - 4 } & & Control & Drought stress & $\mathbf{( \% )}^{\dagger}$ \\
\hline \multirow{4}{*}{2010} & St 89403 & $195.04 \pm 13.37 \mathrm{a},{ }^{*}$ & $100.80 \pm 5.75 \mathrm{a}$ & 48.3 \\
& St 3792 & $206.64 \pm 25.20 \mathrm{a},{ }^{*}$ & $138.02 \pm 17.63 \mathrm{~b}$ & 33.2 \\
& Agave & $258.97 \pm 4.96 \mathrm{~b},{ }^{*}$ & $131.90 \pm 5.14 \mathrm{~b},{ }^{*}$ & 49.1 \\
& Average & $220.22 \pm 32.74 *$ & $123.57 \pm 19.76 *$ & 43.9 \\
& St 89403 & $175.98 \pm 8.84 \mathrm{a},{ }^{*}$ & $104.27 \pm 3.33 \mathrm{a}$ & 40.8 \\
\multirow{2}{*}{2011} & St 3792 & $144.64 \pm 17.48 \mathrm{~b},{ }^{*}$ & $110.97 \pm 5.12 \mathrm{a}$ & 23.3 \\
& Agave & $167.70 \pm 12.72 \mathrm{a}, \mathrm{b},{ }^{*}$ & $109.70 \pm 8.05 \mathrm{a},{ }^{*}$ & 34.6 \\
& Average & $162.77 \pm 18.45 *$ & $108.31 \pm 6.08 *$ & 33.5 \\
\hline
\end{tabular}

a,b Genotype and means followed by different letters within the same column differ significantly at $P \leq 0.05$;

* Significance of the difference in tuber yield between the years at $P \leq 0.05$; ${ }^{\dagger}$ Differences between the control and drought stress variants were all significant at $P \leq 0.05$; SD: standard deviation.

The potato genotypes varied in their reaction to drought stress (Table 2). In 2010, cv. Agave exhibited the greatest loss in tuber yield, while in 2011 the clone St 89403 revealed the highest yield reduction. St 3792 was less strong affected by drought than the others, in both test years.

The decrease of yield was to be expected, since drought is one of the most important environmental stresses limiting the productivity of crop plants [18]. Plants need sufficient water for their growth, and above all photosynthesis is associated with water use [19]. Potatoes react extremely sensitively towards drought. Especially, water shortage during the tuber balking period impairs the yield to a large 
extent [20,21], and even a short period of drought can lead to great losses in marketable tuber yield [22]. The reduction of tuber yield due to drought (Table 2) was important for this work. It clearly demonstrated that drought stress had been successfully applied thus enabling the study of its effect on antioxidants accumulated in tuber tissue.

In 2011 all genotypes had a lower yield than in 2010 (Table 2). The differences between the two years were statistically significant at a level of $P \leq 0.05$ for control plants and drought stressed plants. However, the yield reduction was less pronounced within drought stressed plants $(-12.4 \%)$ than within control plants grown with sufficient water supply $(-26.1 \%)$. The diminished yield may have been caused by the weather that had been cool and cloudy during the main growing period in 2011, while it had been sunny and warm in 2010. The photosynthesis in plants urgently needs the energy of sun light [19], and apart from water, a high tuber yield can only be obtained with adequate light [22], i.e., conditions which were less fulfilled in 2011. In addition, the second drought period inserted 11 weeks after planting in 2011 may have contributed to a decreased tuber yield in this last year.

\subsection{Effect of Drought Stress on Anthocyanins}

Anthocyanins which can occur in almost all vegetative organs (roots, stems, axilarry buds, leaves, stolons, tubers, etc.) are part of the antioxidant system in plants [6] and have been well documented as bioactive plant polyphenols [23]. The radical scavenging capacity of Ac pigments has been shown to be up to four times greater than those of vitamins E and C [13,24].

The two clones St 89403 and St 3792 revealed relatively high amounts of Ac in control tubers and in drought stressed tubers (Table 3), while no colour pigment could be detected in the appropriate tuber samples of the yellow fleshed cv. Agave (data are not shown in Table 3). In each year, St 89403 had on average higher pigment contents in both tuber types than St 3792 (Table 3). However, all differences in Ac between the two purple clones were statistically not significant.

In both years, St 89403 had less Ac in tubers exposed to drought stress than in those grown under control conditions (Table 3). In 2010, the clone St 3792 exhibited similar amounts of Ac in both tuber types, while in 2011 its drought stressed tubers had slightly higher pigment contents than the control tubers. However, altogether, the differences in Ac between the control and drought stressed tubers were not significant. Despite the fact that two drought periods were applied, the Ac levels were higher on average in 2011 than in 2010, a year with only one drought period (Table 3). This may support the notion that the effect of drought stress on the anthocyanins is less pronounced.

In 2011 the two purple clones displayed notably higher concentrations of Ac pigments in control (St 89403, +52.9\%; St 3792, +54.8\%) and drought stressed tubers (St 89403, +65.6\%; St 3792, $+54.1 \%$ ) than in the year 2010 (Table 3), as already mentioned. The differences in Ac between the years were statistically significant. It seems that the effect of the year on Ac pigment content was more pronounced than that of drought stress. A similar clear effect of the year on the total amount of Ac in purple potatoes has been reported recently [12]. 
Table 3. Total amounts of anthocyanins in lyophilized tissue samples prepared from control and drought stressed tubers grown in 2010 and 2011 (Mean \pm SD; $n=4$ ).

\begin{tabular}{|c|c|c|c|}
\hline \multirow{2}{*}{ Years } & \multirow{2}{*}{ Genotypes } & \multicolumn{2}{|c|}{ Anthocyanins (mg $\left.100 \mathrm{~g}^{-1}\right)$} \\
\hline & & Controls & Drought stress \\
\hline \multirow{3}{*}{2010} & St 89403 & $272 \pm 17$ & $218 \pm 1$ \\
\hline & St 3792 & $199 \pm 3$ & $193 \pm 2$ \\
\hline & Average & $235 \pm 43$ & $206 \pm 15$ \\
\hline \multirow{3}{*}{2011} & St 89403 & $416 \pm 3$ & $361 \pm 21$ \\
\hline & St 3792 & $308 \pm 7$ & $357 \pm 8$ \\
\hline & Average & $362 \pm 63$ & $359 \pm 13$ \\
\hline
\end{tabular}

The differences in Ac between the years were all statistically significant at $P \leq 0.01$. The differences in Ac between the genotypes and between the control and drought stress variants were not significant.

In many plant species the biosynthesis of anthocyanins is initiated by stress, e.g., strong light, UV-B radiation and temperature extremes [6], and their induction by cooler temperatures is well known too $[25,26]$. Also in the present study such conditions were found to be more optimal. Thus, the Ac levels were higher in 2011, a year with cooler temperatures in July (Table 1), than in 2010, a year with a warm summer (Table 3). This tendency however was contrary to that observed for tuber yield (Table 2) and POD activity (Table 4) which were all higher in 2010.

\subsection{The Effect of Drought and Wounding Stress on the Peroxidase Activity}

The peroxidase enzymes are also part of the antioxidant system in plants [6], and they are involved in resistance responses against plant pathogenic micro-organisms [27]. This was the reason, why besides drought stress the effect of wounding stress on the POD activity was also studied.

In both years, St 89403 was outstanding and had many times higher POD activity than St 3792 and cv. Agave in its control tubers grown with sufficient water supply and in tubers that were imposed to drought stress (Table 4). Also after wounding, St 39403 displayed considerably higher peroxidase activity in all tuber types than the other genotypes. In 2010 and 2011 all differences in POD between St 89403 and the latter were statistically significant. St 3792 and cv. Agave differed less strongly in their POD activities (Table 4).

In 2010, St 89403 displayed a higher POD activity in fresh and wounded tubers exposed to drought stress than in the appropriate control tubers (Table 4). These differences were statistically significant in the case of fresh tubers $(\mathrm{P} \leq 0.05)$, however not when its wounded tubers were regarded. In 2011, all differences in POD activity between control and drought stressed tubers of St 89403 were statistically not significant. The other genotypes, St 3792 and cv. Agave reacted less sensitively in their POD activity to drought in both test years (Table 4). In summary, the effect of drought stress on the POD expressed in tuber tissue was statistically not significant. This result was in agreement with Ac discussed previously (Table 3 ).

After wounding, the control tubers of all three genotypes revealed an increase in POD activity, a tendency observed in both years (Table 4). Also tubers that were exposed to drought stress displayed a higher POD activity after wounding, except those of St 39403 grown in 2010 (Table 4). Apart from this fact, all differences in POD between fresh and wounded tubers of the appropriate control and 
drought stress variants were statistically significant. With it, the effect of wounding stress on the POD was more evident than that of drought stress. Together with plant phenols, peroxidases are involved in lignin and suberin formation associated with wound healing processes [28,29] and resistance expression in plants [27]. Doubtless, wounds are a permanent threat for potatoes in agriculture and serve as a major entry for plant pathogenic micro-organisms causing tissue decay. In nature, potatoes are programmed in order to survive and this aim may be less endangered by occasional drought than by a pathogenic attack via wounds. Consequently, the wound healing processes must be facilitated and within this framework the POD was introduced (Table 4). It is noteworthy that the purple clone St 39403 displayed a clear rise in enzyme activity after wounding, despite a relatively high POD level in its fresh tissue (Table 4). This fact may underline the role of POD within wound stress responses.

Table 4. Peroxidase activity in fresh tissue and $24 \mathrm{~h}$ after wounding of the control and drought stressed tubers grown in 2010 and 2011 (Mean $\pm \mathrm{SD} ; n=4$ ).

\begin{tabular}{cccccc}
\hline \multirow{2}{*}{ Years } & Genotypes & \multicolumn{4}{c}{ Peroxidase activity $\left(\mathbf{U ~} \boldsymbol{\mu L}^{-1}\right)$} \\
\cline { 3 - 6 } & & Fresh & Wounded & Dresh & Drought stress \\
& & $0.85 \pm 0.18 \mathrm{a},{ }^{*}$ & $0.97 \pm 0.18 \mathrm{a}$ & $1.32 \pm 0.06 \mathrm{a},{ }^{*}$ & $1.31 \pm 0.27 \mathrm{a},{ }^{*}$ \\
\multirow{2}{*}{2010} & St 89403 & $0.19 \pm 0.05 \mathrm{~b}$ & $0.26 \pm 0.03 \mathrm{~b}$ & $0.16 \pm 0.02 \mathrm{~b},{ }^{*}$ & $0.21 \pm 0.03 \mathrm{~b},{ }^{*}$ \\
& St 3792 & $0.24 \pm 0.02 \mathrm{~b},{ }^{*}$ & $0.37 \pm 0.01 \mathrm{~b},{ }^{*}$ & $0.24 \pm 0.02 \mathrm{c},{ }^{*}$ & $0.34 \pm 0.04 \mathrm{~b}$ \\
& Agave & $0.43 \pm 0.33 *$ & $0.53 \pm 0.34 *$ & $0.57 \pm 0.55 *$ & $0.62 \pm 0.53$ \\
& Average & $0.59 \pm 0.05 \mathrm{a},{ }^{*}$ & $0.70 \pm 0.06 \mathrm{a}$ & $0.60 \pm 0.10 \mathrm{a},{ }^{*}$ & $0.83 \pm 0.10 \mathrm{a},{ }^{*}$ \\
& St 89403 & $0.16 \pm 0.02 \mathrm{~b}$ & $0.25 \pm 0.04 \mathrm{~b}$ & $0.12 \pm 0.01 \mathrm{~b},{ }^{*}$ & $0.27 \pm 0.01 \mathrm{~b},{ }^{*}$ \\
& St 3792 & $0.13 \pm 0.02 \mathrm{~b}, *$ & $0.24 \pm 0.01 \mathrm{~b}, *$ & $0.14 \pm 0.01 \mathrm{~b},{ }^{*}$ & $0.29 \pm 0.01 \mathrm{~b}$ \\
& Agave & $0.29 \pm 0.22 *$ & $0.40 \pm 0.23 *$ & $0.29 \pm 0.24 *$ & $0.46 \pm 0.28$ \\
\hline
\end{tabular}

a,b,c Genotype means followed by different letters in the same column differ significantly at $P \leq 0.05$;

* Difference between the years is significant at the level $P \leq 0.05$.

Moreover, it should be mentioned that the POD activity was higher on average in 2010 than in 2011 (Table 4). This tendency was contrary to that observed for the Ac contents that were smaller in 2010 compared to the year 2011 (Table 3). In fact, the POD activity was increased when the amounts of anthocyanins were decreased, and vice versa. A similar inverse correlation between POD activity and anthocyanins was noticed in juvenile and adult leaves of Gazania splendens, i.e., the Ac level of adult leaves was smaller than those of juvenile forms, probably due to inhibition of Ac biosynthesis [30]. However, it is also possible that the anthocyanins function as a reservoir (or preferred substrate) that can be mobilized in order to form other phenylpropanoid products such as lignin and cell wall cross-linking compounds, as suggested similarly for chlorogenic acid [15]. In this frame it is important that several functions of antioxidant enzymes such as scavenging of free radicals can also be conducted by Ac, and in addition the latter can prevent inactivation of antioxidant enzymes [6]. Accordingly, antioxidant enzymes and Ac may act complementarily in order to maintain the antioxidant potential in plant tissue, which is regarded as a key feature in the acclimation of plants to environmental stress [6]. Hence, potato genotypes containing such colour pigments may have an advantage in nature. 


\subsection{The Effect of Drought and Wounding Stress on Antioxidants}

The different types of antioxidants measured as ascorbic acid (ACE) and trolox equivalent (TXE) may also be involved in acclimation of plants to environmental stress [6]. In addition, they may have beneficial effects on human health when consumed within the diet $[8,10,16]$.

\subsubsection{Ascorbic Acid Equivalent}

The three genotypes varied considerably in their ACE values (Table 5). This could be observed in both years, within their fresh and wounded control tubers as well as within fresh and wounded drought stressed tubers. All differences in ACE between the genotypes were statistically significant (Table 5). St 39403 exhibited the highest ACE in all tuber types and in each year, while cv. Agave ranked on the lowest level in this respect. In fact, St 39403 had multiple higher antioxidant capacities than cv. Agave. The high antioxidant activity found in all tuber types of this purple clone (Table 5) coincided with similarly high POD (Table 4) and Ac contents in its tuber tissue (Table 3). These results are in good agreement with other reports on white/yellow fleshed and purple potatoes $[8,10,12]$.

Table 5. Antioxidant activity measured as ascorbic acid equivalent (ACE) in fresh tissue and $24 \mathrm{~h}$ after wounding of the control and drought stressed tubers grown in 2010 and 2011 (Mean $\pm \mathrm{SD} ; n=4)$.

\begin{tabular}{|c|c|c|c|c|c|}
\hline \multirow{3}{*}{ Years } & \multirow{3}{*}{ Genotypes } & \multicolumn{4}{|c|}{$\mathrm{ACE}\left(\mu \mathrm{g} \mathrm{mg^{-1 } )}\right.$} \\
\hline & & \multicolumn{2}{|c|}{ Control } & \multicolumn{2}{|c|}{ Drought stress } \\
\hline & & Fresh & Wounded & Fresh & Wounded \\
\hline \multirow{4}{*}{2010} & St 89403 & $2.36 \pm 0.36 \mathrm{a}, *$ & $2.31 \pm 0.34 \mathrm{a}$ & $2.08 \pm 0.09 \mathrm{a}, *$ & $2.06 \pm 0.20 \mathrm{a}, *$ \\
\hline & St 3792 & $1.14 \pm 0.12 \mathrm{~b}, *$ & $1.29 \pm 0.20 \mathrm{~b}$ & $1.32 \pm 0.24 \mathrm{~b}$ & $1.26 \pm 0.15 b$ \\
\hline & Agave & $0.38 \pm 0.07 \mathrm{c}, *$ & $0.65 \pm 0.07 \mathrm{c}, *$ & $0.21 \pm 0.05 \mathrm{c}$ & $0.53 \pm 0.09 \mathrm{c}$ \\
\hline & Average & $1.29 \pm 0.88 *$ & $1.42 \pm 0.74 *$ & $1.20 \pm 0.81 *$ & $1.28 \pm 0.67 *$ \\
\hline \multirow{4}{*}{2011} & St 89403 & $1.76 \pm 0.11 \mathrm{a}, *$ & $1.94 \pm 0.17 \mathrm{a}$ & $1.61 \pm 0.17 \mathrm{a}, *$ & $1.47 \pm 0.10 \mathrm{a}, *$ \\
\hline & St 3792 & $0.94 \pm 0.07 \mathrm{~b}, *$ & $1.15 \pm 0.05 \mathrm{~b}$ & $0.98 \pm 0.15 b$ & $1.02 \pm 0.13 b$ \\
\hline & Agave & $0.25 \pm 0.04 \mathrm{c}, *$ & $0.50 \pm 0.04 \mathrm{c}, *$ & $0.24 \pm 0.02 \mathrm{c}$ & $0.56 \pm 0.01 \mathrm{c}$ \\
\hline & Average & $0.99 \pm 0.65 *$ & $1.20 \pm 0.62 *$ & $0.94 \pm 0.60 *$ & $1.02 \pm 0.40 *$ \\
\hline
\end{tabular}

a,b,c Genotype means followed by different letters in the same column differ significantly at $P \leq 0.05$;

* Difference between the years is significant at the level $P \leq 0.05$.

In both years, St 39403 displayed a lower ACE in fresh and wounded tubers exposed to drought stress than in its control tubers grown under sufficient water supply (Table 5). The differences were statistically significant $(P \leq 0.05)$, however only within its wounded tubers tested in 2011 . Significant differences in ACE between control and drought stress tubers were also found for cv. Agave $(P \leq 0.05)$, but only within fresh tubers tested in 2010, and generally not in the year 2011. St 3792 remained relatively unchanged in its ACE by drought stress in both years (Table 5). Altogether the differences in ACE between the control and drought stress variants were statistically not significant. It seems that the effect of drought stress on the ACE was less pronounced, as noticed similarly in context with Ac (Table 3) and POD (Table 4). 
After wounding, cv. Agave demonstrated a significant rise of the ACE level $(P \leq 0.001)$ in control and drought stressed tubers (Table 5). A significantly increased ACE $(P \leq 0.05)$ as a result of wounding was also found in control tubers of St 3792 in 2011. However, all other differences in ACE regarding this purple clone were not significant. St 89403 even displayed a slightly reduced ACE after wounding in its control tubers tested in 2010 and in drought stressed tubers of both test years (Table 5). Altogether, the differences in ACE caused by wounding were statistically not significant. Nevertheless, there is growing evidence that plants respond to stress factors by increasing their radical absorbing capacity [15], and also the clear rise of ACE by wounding in cv. Agave concurred with other studies on cultivated and wild Solanum species [14,31].

However, the present results demonstrate that induction of ACE by wounding depends on the genotype and the basic antioxidant activity. Thus, St 39403 with its relatively high basic level of antioxidants exhibited no (control and drought stressed tubers; 2010 and 2011) or only a weak (control tubers in 2011) enhancement of ACE due to wounding (Table 5). This genotype may have sufficient amounts of antioxidants in its tissue in order to respond successfully to wounding stress. On the other hand, cv. Agave with a relatively low basic antioxidant capacity showed a notable rise of ACE on wounding, in control (up to 2-times) and drought stressed tubers (up to 2.5-times). A similar differentiated wound-induced alteration of antioxidant activities was found in several cultivated and wild Solanum species [14]. Plant phenols including caffeic acid derivatives [32] and flavonoids including quercetin and its glycosides all generate antioxidant activity [33], and they are involved in pathogen defence [34]. Together with peroxidase enzymes, all these phenolic compounds play a role within wound healing processes [28,29]. In fact, they insure rapid wound healing [35], seen as the most critical point for resistance expression in potatoes [36]. This may explain why cv. Agave induced its ACE much more in response to wounding than the purple clones with their high basic antioxidant level (Table 5).

Moreover, it should be mentioned that the ACE level was significantly higher in 2010 than in 2011, a tendency observed for nearly all tuber types (Table 5). In control tubers the rise in antioxidants by wounding was on average higher in $2011(+21 \%)$ than in $2010(+10 \%)$, when the ACE was generally higher in all tuber types (Table 5). In drought stressed tubers, the increase of ACE by wounding was less strong and different in both test years, and amounted on average to $8.5 \%$ (2011) and $6.7 \%$ (2010), respectively.

\subsubsection{Trolox Equivalent}

The three potato genotypes also differed in their TXE measured in fresh and wounded control and drought stressed tubers in both test years (Table 6). In 2010, St 89403 displayed the highest TXE level in all tuber types among the three genotypes. Also in 2011 this purple clone reached a relatively high TXE, above all in its fresh and wounded control tubers. Again, St 89403 had many-times higher antioxidant capacities than cv. Agave, which generally revealed the lowest amounts of lipid soluble antioxidants in all tissue types (Table 6). The differences in TXE between the three potato genotypes were all statistically significant at a level of $P \leq 0.05$ within control tubers (Table 6). Regarding drought stressed tubers, cv. Agave differed significantly from the two purple clones $(P \leq 0.05)$, which 
did not differ notably in their TXE. A relatively high TXE in all tuber types of the two purple clones coincided with similar high ACE (Table 5), POD (Table 4) and Ac levels (Table 3).

In 2010, St 3792 had a significantly higher TXE $(P \leq 0.05)$ in fresh drought stressed tubers than in appropriate control tubers grown with sufficient water supply (Table 6). In 2011, St 39403 displayed a significantly lower TXE $(P \leq 0.05)$ in its wounded drought stressed tubers than in the control tubers.

Table 6. Antioxidant activity measured as trolox equivalent (TXE) in fresh tissue and $24 \mathrm{~h}$ after wounding the control and drought stressed tubers grown in 2010 and 2011 $(\mathrm{Mean} \pm \mathrm{SD} ; n=4)$.

\begin{tabular}{|c|c|c|c|c|c|}
\hline \multirow{3}{*}{ Years } & \multirow{3}{*}{ Genotypes } & \multicolumn{4}{|c|}{ TXE $\left(\mu \mathrm{g} \mathrm{mg}^{-1}\right)$} \\
\hline & & \multicolumn{2}{|c|}{ Control } & \multicolumn{2}{|c|}{ Drought stress } \\
\hline & & Fresh & Wounded & Fresh & Wounded \\
\hline \multirow{4}{*}{2010} & St 89403 & $4.33 \pm 0.25 \mathrm{a}, *$ & $4.55 \pm 0.38 \mathrm{a}, *$ & $4.46 \pm 0.48 \mathrm{a}, *$ & $4.26 \pm 0.31 \mathrm{a}, *$ \\
\hline & St 3792 & $3.67 \pm 0.38 \mathrm{~b}, *$ & $3.56 \pm 0.27 b, *$ & $4.30 \pm 0.28 \mathrm{a}, *$ & $3.60 \pm 0.41 b$ \\
\hline & Agave & $0.34 \pm 0.02 \mathrm{c}, *$ & $0.61 \pm 0.05 \mathrm{c}$ & $0.28 \pm 0.03 \mathrm{~b}$ & $0.62 \pm 0.06 \mathrm{c}, *$ \\
\hline & Average & $2.78 \pm 1.84 *$ & $2.91 \pm 1.76 *$ & $3.01 \pm 2.04 *$ & $2.82 \pm 1.68 *$ \\
\hline \multirow{4}{*}{2011} & St 89403 & $2.92 \pm 0.28 \mathrm{a}, *$ & $3.32 \pm 0.32 \mathrm{a}, *$ & $2.81 \pm 0.21 \mathrm{a}, *$ & $2.49 \pm 0.11 \mathrm{a}, *$ \\
\hline & St 3792 & $2.50 \pm 0.18 \mathrm{a}, *$ & $2.36 \pm 0.11 \mathrm{~b}, *$ & $2.97 \pm 0.53 \mathrm{a}, *$ & $2.78 \pm 0.34 \mathrm{a}$ \\
\hline & Agave & $0.27 \pm 0.03 \mathrm{~b}, *$ & $0.59 \pm 0.09 \mathrm{c}$ & $0.26 \pm 0.03 \mathrm{~b}$ & $0.50 \pm 0.02 \mathrm{~b}, *$ \\
\hline & Average & $1.90 \pm 1.22 *$ & $2.09 \pm 1.20 *$ & $2.01 \pm 1.33 *$ & $1.92 \pm 1.07 *$ \\
\hline
\end{tabular}

a,b,c Genotype means followed by different letters in the same column differ significantly at $P \leq 0.05$;

* Difference between the years is significant at the level $P \leq 0.05$.

All other differences in TXE between tubers grown under control conditions and those exposed to drought stress were statistically not significant. With it, the effect of drought stress on the TXE was less pronounced, similarly as noticed for the ACE (Table 5), POD (Table 4) and Ac (Table 3).

After wounding, cv. Agave displayed a significant increase of the TXE $(P \leq 0.01)$ in its control and drought stressed tubers, a tendency observed in both test years (Table 6). St 3792, on the other hand, exhibited a significantly lower TXE $(P \leq 0.05)$ after wounding of its drought stressed tubers grown in 2010, similar to St 39403 in 2011. Within the purple clones, all other differences in TXE caused by wounding were statistically not significant.

It was interesting, that cv. Agave with its low concentration of antioxidants revealed a stronger rise in TXE on wounding (up to 2.2-times) than the purple clones, which generally ranked on a higher level in this respect (Table 6). These findings were in agreement with the ACE (Table 5) and as already discussed in this respect, the differentiated wound-induced alteration in TXE may be associated with resistance expression in tuber tissue. Furthermore, it is noteworthy that the TXE was on average higher in 2010 than in 2011, whereby the difference between the years was statistically significant (Table 6). This result was in agreement with ACE (Table 5), POD (Table 4) and tuber yield (Table 2) which were all on a higher level in 2010, compared to the year 2011. 


\subsection{Correlations between the Parameters}

There were significant correlations between ACE and TXE measured both in fresh and wounded control tubers as well as in fresh and wounded drought stressed tubers in 2010 and 2011 (Table 7). Significant correlations were also found between the two experimental years for ACE and TXE (Table 7). In addition, significant correlations for ACE and TXE were detected between control and drought stressed tubers as well as between fresh and wounded tubers, in each year (Table 8).

Table 7. Correlations between ACE and TXE measured in 2010 and 2011, and correlations between the two test years for ACE and TXE measured in 2010 and 2011.

\begin{tabular}{ccccc}
\hline \multirow{2}{*}{ Correlations between } & \multicolumn{2}{c}{ Control } & \multicolumn{2}{c}{ Drought stress } \\
\cline { 2 - 5 } & Fresh & Wounded & Fresh & Wounded \\
\hline ACE and TXE & & & & \\
2010 & 0.83 & 0.89 & 0.91 & 0.91 \\
2011 & 0.91 & 0.97 & 0.86 & 0.80 \\
2010 and 2011 & & & & \\
ACE & 0.95 & 0.92 & 0.95 & 0.93 \\
TXE & 0.99 & 0.96 & 0.97 & 0.92 \\
\hline
\end{tabular}

All correlation coefficients were statistically significant at $P \leq 0.01 ; n=12$.

Table 8. Correlations between control and drought stressed tubers, and correlations between fresh and wounded tubers for ACE and TXE measured in 2010 and 2011.

\begin{tabular}{cccccc}
\hline \multirow{2}{*}{ Parameters } & Years & \multicolumn{2}{c}{$\begin{array}{c}\text { Correlation between } \\
\text { control and drought stress }\end{array}$} & \multicolumn{2}{c}{$\begin{array}{c}\text { Correlation between fresh } \\
\text { and wounded tissue }\end{array}$} \\
\cline { 3 - 6 } & & Fresh & Wounded & Control & Drought stress \\
\hline \multirow{2}{*}{ ACE } & 2010 & 0.93 & 0.93 & 0.99 & 0.98 \\
& 2011 & 0.95 & 0.98 & 0.99 & 0.97 \\
\multirow{2}{*}{ TXE } & 2010 & 0.97 & 0.96 & 0.97 & 0.96 \\
& 2011 & 0.94 & 0.87 & 0.98 & 0.99 \\
\hline
\end{tabular}

All correlation coefficients were statistically significant at $\mathrm{P} \leq 0.01 ; n=12$.

This clear correlation between ACE and TXE is in a good agreement with recent studies on cultivated and wild Solanum species [14] and may show that water and lipid soluble antioxidants present in tuber tissue are closely related.

Moreover, the ACE values were significantly (all, $P \leq 0.01$ ) correlated with anthocyanins present in control tubers in $2010(r=0.92)$ and $2011(r=0.99)$, and in drought stressed tubers in $2010(r=0.99)$. These correlations between ACE and Ac concurred with other studies on purple fleshed potatoes [12], and underline the fact that anthocyanins function as antioxidants [6]. Similarly, the TXE data were correlated with Ac present in control tubers grown in $2010(r=0.98 ; P \leq 0.01)$ and $2011(r=0.81$; $P \leq 0.05)$. Correlations between TXE and Ac were also found within drought stressed tubers. However, these were statistically not significant in both years, similar to the correlations found between ACE and Ac detected in 2011. Furthermore, the ACE data were significantly correlated with POD (Table 9). This is not surprising, since peroxidases are known to function as antioxidants [6]. Moreover, correlations were found between TXE and POD. However, the latter were less significant than the 
correlations observed between ACE and POD (Table 9). Altogether the results may demonstrate that the different types of antioxidants present in fresh and wounded control and drought stressed tubers are closely associated.

Table 9. Correlations between ACE and peroxidase enzyme (POD), and correlations between TXE and POD measured in 2010 and 2011.

\begin{tabular}{cccccc}
\hline \multirow{2}{*}{$\begin{array}{c}\text { Correlations } \\
\text { between }\end{array}$} & \multirow{2}{*}{ Year } & \multicolumn{2}{c}{ Control } & \multicolumn{2}{c}{ Drought stress } \\
\cline { 3 - 6 } & & Fresh & Wounded & Fresh & Wounded \\
\hline \multirow{2}{*}{ ACE and POD $^{\text {a }}$} & 2010 & 0.86 & 0.82 & 0.76 & 0.76 \\
& 2011 & 0.89 & 0.87 & 0.76 & 0.83 \\
TXE and POD $^{b}$ & 2010 & 0.53 & 0.57 & 0.47 & 0.55 \\
& 2011 & 0.64 & 0.75 & 0.38 & 0.35 \\
\hline
\end{tabular}

a correlations were all statistically significant at a level of $P \leq 0.01(n=12) ;{ }^{\mathrm{b}}$ Correlations were statistically significant within fresh $(P \leq 0.05)$ and wounded $(P \leq 0.01)$ control tubers harvested in $2011(n=12)$.

\section{Experimental Section}

\subsection{Plant Materials}

The study was carried out on three potato genotypes, all from the breeding company NORIKA, Groß Lüsewitz, Germany. In vitro plants of cv. Agave (early season) and of the two breeding clones St 89403 and St 3792 (both early-mid season) were used for planting. Each randomized experimental set for (a) the control and (b) the drought stress variant was carried out with four replications, including four plants per genotype and replication. The potato plants were grown in pots of $130 \mathrm{~mm}$ in diameter from April to September in the years 2010 and 2011 in a glasshouse. The mean daily temperatures during the main growing periods are presented in Table 1. Fertilizer, insecticides, fungicides and all other treatments were conducted according to local agronomic practice, and drought stress was applied as detailed below. After harvest in September, the tuber yield was determined for each plant. The tubers were stored in a controlled environment at $5{ }^{\circ} \mathrm{C}$ until the tissue samples were prepared for the assay of anthocyanins, POD activities and antioxidants including ACE (Ascorbic acid equivalent) and TXE (Trolox equivalent) as described below.

\subsection{Drought Stress Application}

The control plants were watered daily during the whole growing period. Plants involved in the drought stress experiments were watered daily up to seven weeks after planting (start of tuber initiation-growth stage code 40400 according to Meier [37]) before the water supply was completely stopped during a time-span of 6 days. After that time, each plant received only $50 \mathrm{~mL}$ of water per day, and from the middle of August until the end of experiments the amounts of water were further reduced to $30 \mathrm{~mL}$ per day.

In 2010 the weather was warm and sunny during the main growing period, especially in July (Table 1). Therefore, only one drought period was applied in the first year. In 2011, the weather was cool and cloudy at that time, so that 11 weeks after planting a second drought period for 6 days was inserted without the risk of plant death. 


\subsection{Assay of Anthocyanins}

As an average sample, five similar sized tubers were taken from each genotype and replication. For the assay of anthocyanins, the tubers from two replications of each genotype were pooled. Next, all tubers were halved and a $2 \mathrm{~mm}$ thick tissue slice was excised from each of the 20 tuber halves. The slices were cut into small pieces of which $25 \mathrm{~g}$ was lyophilized. The lyophilized tissue sample was ground by a mortar and pestle, and the tissue powder was used for measurement of anthocyanins according to the method detailed by Fuleki and Francis [38] with modifications.

The tissue powder $(600 \mathrm{mg})$ was suspended in $20 \mathrm{ml}$ of an extraction solvent containing $90 \%$ ethanol in $1 \mathrm{~mol} \mathrm{~L}^{-1} \mathrm{HCl}$ (Roth, Karlsruhe, Germany both) $(85: 15, \mathrm{v} / \mathrm{v})$. The suspension was shaken for $90 \mathrm{~min}$ at $4{ }^{\circ} \mathrm{C}$ on a laboratory shaker and then centrifuged at $12,000 \times \mathrm{g}$ for $15 \mathrm{~min}$ at $4{ }^{\circ} \mathrm{C}$. Subsequently, $5 \mathrm{~mL}$ of the supernatant was diluted with $50 \mathrm{~mL}$ of the extraction solvent and used for measurement of anthocyanins as malvidin-3-p-coumaroylglycoside (Extinction coefficient: $3.02 \times 10^{4}$; Molecular weight: $718 \mathrm{~g} \mathrm{~mol}^{-1}$ at $545 \mathrm{~nm}$ on a UV spectrophotometer (Kontron Instruments, Neufahrn, Germany). Measurements were carried out in triplicate with $\mathrm{SD} \leq 5 \%$.

\subsection{Preparation of Potato Cylinder Samples}

As an average sample, ten tubers were taken from each genotype and replication. The tubers were halved, and using a cork borer of $5 \mathrm{~mm}$ in diameter two cylinders were cut from the outer region of each half and each tuber. In order to test the effect of wounding on the peroxidase enzyme activity and on the concentration of antioxidants comprising their water (ACE) and lipid soluble fractions (TXE) two cylinder samples were taken per genotype and assay: the first one was excised from (i) fresh tuber tissue and a second was prepared (ii) $24 \mathrm{~h}$ after wounding of the tubers. Before cutting the second sample, the tuber halves of each experimental set were stored for $24 \mathrm{~h}$ at $20{ }^{\circ} \mathrm{C}$ with the wound-surface upward on a moist filter paper placed in a plastic box which was covered.

\subsection{Assay of Peroxidase Activity}

In order to determine the POD enzyme activity, a $2 \mathrm{~mm}$ thick tissue slice was excised by means of a scalpel from the upper wound of each tissue cylinder prepared from tuber halves as detailed above. The slices were pooled, and $2 \mathrm{~g}$ of the tissue slices was ground under liquid nitrogen with a mortar and pestle. The homogenate was centrifuged at $13,000 \times \mathrm{g}$ for $5 \mathrm{~min}$ at $4{ }^{\circ} \mathrm{C}$. The supernatant was diluted and used for the assay of POD activity according to Bi et al. [39] with modifications.

A sample of $950 \mu \mathrm{L}$ of sodium-phosphate buffer $\left(50 \mathrm{mmol} \mathrm{L}^{-1}\right.$ of $\mathrm{NaH}_{2} \mathrm{PO}_{4}$; Merck, Darmstadt, Germany) adjusted to $\mathrm{pH} 6.5$ with $1 \mathrm{~mol} \mathrm{~L}^{-1}$ of $\mathrm{NaOH}$ (Merck) and supplemented with $10 \mathrm{mmol} \mathrm{L}^{-1}$ of hydrogen peroxide (Roth) and $20 \mathrm{mmol} \mathrm{L}^{-1}$ of guaiacol (Sigma-Aldrich, Taufkirchen, Germany) was thoroughly mixed with $50 \mu \mathrm{L}$ of the extract dilution. Measurement of enzyme activity at $470 \mathrm{~nm}$ on a UV spectrophotometer (Kontron Instruments, Neufahrn, Germany) using the kinetic program was carried out at $20^{\circ} \mathrm{C}$. One enzyme unit was defined as the increase in 0.1 absorbance units per minute and micro litre of the extract. Measurements were performed in triplicate with $\mathrm{SD} \leq 5 \%$. 


\subsection{Assay of Antioxidants}

For measurement of antioxidants, $2 \mathrm{~mm}$ thick slices were cut from the tissue cylinders prepared from tuber halves as detailed in section 3.4. The slices were pooled, and $3 \mathrm{~g}$ of the tissue slice was ground under liquid nitrogen with a mortar and pestle. The homogenate was suspended in $20 \mathrm{~mL}$ of $85 \%(\mathrm{v} / \mathrm{v})$ ice cold ethanol (Roth, Karlsruhe, Germany). The suspension was stored on ice, occasionally shaken, and after $1 \mathrm{~h}$ centrifuged at $8000 \times \mathrm{g}$ and $4{ }^{\circ} \mathrm{C}$ for $10 \mathrm{~min}$. The supernatant was diluted and used for measurement of antioxidants on a Photochem instrument (AnalytikJena AG, Germany), utilizing an ACW kit for water soluble and ACL kit for lipid soluble antioxidants according to the manufacturer's recommendations (AnalytikJena AG). This photo-chemiluminescent method (PCL) was described recently by Popov and Lewin [40].

The concentration of antioxidants was calculated by means of an ascorbic acid calibration curve for hydrophilic antioxidants (ACE, ascorbic acid equivalent) and a trolox calibration curve (TXE, trolox equivalent), using the Photochem software package. Results were expressed in microgram equivalents in antioxidant activity of the reference compound, i.e., as ascorbic acid equivalent (ACE) and as trolox equivalent (TXE) per milligram of fresh weight, respectively. Measurements were carried out in triplicate with $\mathrm{SD} \leq 5 \%$.

\subsection{Statistical Analyses}

The results in the Tables $2-5$ are presented as mean values \pm standard deviations (SD; $n=4)$. To assess the effect of drought stress on tuber yield, anthocyanins, ACE, TXE and POD a generalized linear model for the analysis of variance was applied, using the SAS 9.2 statistical package (PROC GLM, Tukey-test, SAS Institute Inc., Cary, NC, USA). The latter was also used in order to study the effect of wounding, the year and the genotype on all these parameters. $P \leq 0.05$ was considered statistically significant.

Correlations (Pearson) between individual parameters were calculated using the SAS 9.2 statistical package (Procedure CORR). $P \leq 0.05$ was regarded to be statistically significant.

\section{Conclusions}

The results revealed that drought stress clearly diminished the tuber yield but in both years had no significant effect on Ac, POD, ACE and TXE. This is an important finding, especially with regard to the expected climate changes leading to higher frequency of drought.

The POD activity increased notably upon wounding in control and drought stressed tubers, a result which underlines the role of POD in wound stress responses of potatoes. Also the ACE and TXE were enhanced by wounding. However, this was dependent on the potato genotype. The yellow fleshed cv. Agave with its low basic antioxidant potential showed a significant raise in ACE and TXE after wounding, while the two purple clones that ranked on a higher level in this respect were less affected. Generally, the effect of wound stress on the POD, ACE and TXE was more pronounced than that of drought stress. Wounding may be a greater threat to potatoes, since wounds serve as a major entry for plant pathogenic micro-organisms causing tissue decay. In addition, the genotype and the year had a 
clear effect on Ac, POD, ACE and TXE levels, and also these effects were more evident than that of drought stress.

Among the genotypes, the purple clone St 89403 had the highest amount of antoxidants, while the yellow fleshed cv. Agave exhibited the lowest level. Compared to starch, proteins and celluloses as major constituents of potatoes, antioxidants including enzymes, vitamins $\mathrm{C}$ and $\mathrm{E}$, plant phenols and anthocyanins are produced in relatively small amounts $[41,42]$. Nevertheless, such phytochemicals could be profitable for the nutritional and health value of potatoes $[1,2,16]$.

\section{Acknowledgment}

Ilona Schollenberg is thanked for excellent technical assistance.

\section{References}

1. Pham-Huy, L.A.; He, H.; Pham-Huyc, C. Free radicals, antioxidants in disease and health. Int. J. Biomed. Sci. 2008, 4, 89-96.

2. Johnson, I.T.; Williamson, G.; Musk, S.R.R. Anticarcinogenic factors in plant foods: A new class of nutrients? Nutr. Res. Rev. 1994, 7, 175-204.

3. Block, G.; Patterson, B.; Subar, A. Fruit, vegetables and cancer prevention: A review of the epidemiological evidence. Nutr. Cancer 1991, 18, 1-29.

4. Temple, N.J.; Gladwin, K. Fruit, vegetable, and the prevention of cancer: Research challenges. Nutrition 2003, 19, 467-470.

5. Thompson, H.J.; Heimendinger, J.; Haegele, A.; Sedlacek, S.M.; Gillette, C.; O’Neill, C.; Wolfe, P.; Conry, C. Effect of increased vegetable and fruit consumption on marker of oxidative cellular damage. Carcinogenesis 1999, 20, 2261-2266.

6. Hatier, H.B.; Gould, K.S. Anthocyanin Function in Vegetative Organs. In Anthocyanins: Biosynthesis, Functions and Applications; Gould, K., Davies, K., Winefield, C., Eds.; Springer Science + Business Media, LLC: New York, NY, USA, 2009; pp. 1-19.

7. Stushnoff, C.; Holm, D.; Thompson, M.D.; Jiang, W.; Thompson, H.J.; Joyce, N.I.; Wilson, P. Antioxidant properties of cultivars and selections from the Colorado potato breeding program. Am. J. Potato Res. 2008, 85, 267-276.

8. Brown, C.R. Antioxidants in potato. Am. J. Potato Res. 2005, 82, 163-172.

9. Friedman, M. Chemistry, biochemistry, and dietary role of potato phenols: A review. J. Agric. Food Chem. 1997, 45, 1523-1520.

10. Brown, C.R.; Culley, D.; Yang, C.P.; Navarre, R.A. Carotenoid and anthocyanin concentrations and associated antioxidant values in high pigment potatoes. Am. J. Potato Res. 2004, 81, 48.

11. Lachman, J.; Hamouz, K. Red and purple coloured potatoes as a significant antioxidant source in human nutrition: A review. Plant Soil Environ. 2005, 51, 477-482.

12. Wegener, C.B.; Jansen, G.; Jürgens, H.U.; Schütze, W. Special quality traits of coloured potato breeding clones: Anthocyanins, soluble phenols and antioxidant capacity. J. Sci. Food Agric. 2008, $89,206-215$.

13. Wang, H.; Cao, G.; Prior, R.L. Oxygen radical absorbing capacity of anthocyanins. J. Agric. Food Chem. 1997, 45, 304-309. 
14. Wegener, C.B.; Jansen, G. Antioxidant capacity in cultivated and wild Solanum species: The effect of wound stress. Food Funct. 2010, 1, 209-218.

15. Grace, S.C. Phenolics as Antioxidants. In Antioxidants and Rreactive Oxygen Species; Smirnoff, N., Ed.; Blackwall Publishing Ltd.: Oxford, UK, 2005; pp. 141-168.

16. Vinson, J.A.; Demkosky, C.A.; Navarre, D.A.; Smyda, M.A. High-antioxidant potatoes: Acute in vivo antioxidant source and hypotensive agent in humans after supplementation to hypertensive subjects. J. Agric. Food Chem. 2012, 60, 6749-6754.

17. Dixon, R.A.; Paiva N.L. Stress induced phenylpropanoid metabolism. Plant Cell 1995, 7, 1085-1097.

18. Bohnert, H.J.; Nelson, D.E.; Jensen, R.G. Adaptations to environmental stress. Plant Cell 1995, 7, 1099-1111.

19. Heldt, H.W. Photosynthesis is Associated with Water Consumption. In Plant Biochemistry; Heldt, H.W., Ed.; Spektrum Akademischer Verlag: Berlin, Germany, 2003; pp. 221-251.

20. Van Loon, C.D. The effect of water stress on potato growth, development and yield. Am. Potato J. 1981, 58, 51-69.

21. Levy, D. The response of potatoes to a single transient heat or drought stress imposed at different stages of tuber growth. Potato Res. 1985, 28, 415-424.

22. Vayda, M.E. Environmental Stress and Its Impact on Tuber Yield. In Potato Genetics; Bradshaw, J.E., Mackay, G.R., Eds.; CAB International: Wallingford, UK, 1994; pp. 239-261.

23. Hooper, L.; Cassidy, A. A review of the health care potential of bioactive compounds. J. Agric. Food Chem. 2006, 86, 1805-1813.

24. Rice-Evans, C.A.; Miller, N.J.; Paganga, G. Antioxidant properties of phenolic compounds. Trends Plant Sci. 1997, 2, 152-159.

25. Chalker-Scott, L. Environmental significance of anthocyanins in plant stress responses. Photochem. Phytobiol. 1999, 70, 1-9.

26. Camm, E.L.; McCallum, J.; Leaf, E.; Koupai-Abyazani, M.R. Cold induced purpling of Pinus contorta seedlings depend on previous day length treatment. Plant Cell Environ. 1993, 16, 761-764.

27. Hammerschmidt, R.; Nuckles, E.M.; Kuc, J. Association of enhanced peroxidase activity with systemic resistance of cucumber to Colletotrichum lagenarium. Physiol. Plant Pathol. 1982, 20,73-82.

28. Borchert, R. Time course of spatial distribution of phenylalanine ammonia-lyase and peroxidase activity in wounded potato tuber tissue. Plant Physiol. 1978, 62, 789-793.

29. Espelie, K.E.; Franceschi, V.R.; Kolattukudy, P.E. Immocytochemical localization and time course of appearance of an anionic peroxidase associated with suberization in wound-healing potato tuber tissue. Plant Physiol. 1986, 81, 487-492.

30. Cevahier, G.; Yentür, S.; Yazgan, M.; Ünal, M.; Yilmazer, N. Peroxidase activity in relation to anthocyanin and chlorophyll content in juvenile and adult leaves of "MINI-STAR" Gazania splendens. Pak. J. Bot. 2004, 36, 603-609.

31. Reyes, L.F.; Cisneros-Zevallos, L. Wounding stress increases the phenolic content and antioxidant capacity of purple-flesh potatoes (Solanum tuberosum L.). J. Agric. Food Chem. 2003, $51,5296-5300$. 
32. Chen, J.H.; Ho, C.T. Antioxidant activities of caffeic acid and its related hydroxycinnamic acid compounds. J. Agric. Food Chem. 1997, 45, 2374-2378.

33. Tudela, J.A.; Cantos, E.; Espin, J.C.; Tomas-Barberan, F.A.; Gil, M.I. Induction of antioxidant flavonol biosynthesis in fresh-cut potatoes: Effect of domestic cooking. J. Agric. Food Chem. 2002, 50, 5925-5931.

34. Ghanekar, A.S.; Padwal-Desai, S.R.; Nadkarni, G.B. The involvement of phenolics and phytoalexins in resistance of potato to soft rot. Potato Res. 1984, 27, 189-199.

35. Vance, C.P.; Kirk, T.K.; Sherwood, R.T. Lignification as a mechanism of disease resistance. Ann. Rev. Phytopathol. 1980, 18, 259-288.

36. Lulai, E.C. Tuber Periderm and Disease Resistance. In Compendium of Potato Diseases; Stevenson, W.R., Loria, R., Franc, G.D., Weingartner, D.P., Eds.; APS Press: St. Paul, MN, USA, 2001; pp. 3-6.

37. Meier, U. Growth stages of mono- and dicotyledonous plants. In BBC-Monograph; Meier, U., Ed.; Blackwall Publishing Ltd.: Berlin, Germany, 1997; p. 48.

38. Fuleki, T.; Francis, F.J. Quantitative methods for anthocyanins. 1. Extraction and determination of total anthocyanins in cranberries. J. Food Sci. 1968, 33, 72-77.

39. Bi, J.L.; Felton, G.W.; Murphy, J.B.; Howles, P.A.; Dixon, R.A.; Lamb, C.J. Do plant phenolics confer resistance to specialist and generalist insect herbivores? J. Agric. Food Chem. 1997, $45,4500-4504$.

40. Popov, I.N.; Lewin, G. Photochemiluminescent detection of antiradical activity: IV. Testing of lipid-soluble antioxidants. J. Biochem. Biophys. Methods 1996, 31, 1-8.

41. Buckenhüskes, H.J. Nutritionally relevant aspects of potatoes and potato constituents. In Potato in Progress; Haverkort, A.J., Struik, P.C., Eds.; Academic Publishers: Wageningen, The Netherlands, 2005; pp. 17-26.

42. Jansen, G.; Flamme, W.; Schüler, K.; Vandrey, M. Tuber and starch quality of wild and cultivated potato species and cultivars. Potato Res. 2001, 44, 137-146.

(C) 2013 by the authors; licensee MDPI, Basel, Switzerland. This article is an open access article distributed under the terms and conditions of the Creative Commons Attribution license (http://creativecommons.org/licenses/by/3.0/). 